\section{JANGAN MUPENG (JASA UNDANGAN DAN MAHAR UNTUK Pengantin) SEbagal PELUANG BISNIS}

\author{
Christy Maulidiah, Reski Harisma \\ Dewi Barkah, Riswandi Syam, \\ Cakra Dewandaru, Rafi Ichsanul \\ Iqbal, Anindita Septiarini*
}

Ilmu Komputer, Universitas Mulawarman

\author{
Article history \\ Received : 18-12-2019 \\ Revised : 23-03-2020 \\ Accepted : 21-04-2020

\section{*Corresponding author} \\ Anindita Septiarini \\ Email : \\ anindita.septiarini@gmail.com
}

\begin{abstract}
Abstraksi
Kewirausahaan dapat diciptakan oleh setiap manusia. Kreatifitas manusia menjadi salah satu penyebab terciptanya suatu kewirausahaan, bahkan dari kreatifitas mahasiswa sendiri pun dapat menciptakan suatu kewirausahaan salah satu nya adalah JANGAN MUPENG (Jasa undangan dan mahar untuk pengantin). Sebagian besar dari calon pengantin menginginkan acara yang sesuai dengan keinginan mereka yang terkesan mewah dan elegan namun dengan harga yang terjangkau. Namun sebagian besar dari mereka mengalami kesulitan ketika mencari informasi mengenai undangan yang trendi dan sesuai dengan konsep pernikahan yang mereka inginkan. JANGAN MUPENG di Samarinda memiliki peluang bagus karena jasa pembuatan undangan dan mahar dapat menyesuaikan dengan keinginan calon pengantin. JANGAN MUPENG ini menyediakan jasa pembuatan undangan dan mahar bagi calon pengantin sesuai dengan keinginan mereka. Ditinjau dari keadaan ekonomi masyarakat kota Samarinda yang cenderung mencari dan membeli barang yang murah tetapi tetap berkualitas, optimis bahwa produk jasa yang ditawarkan akan-banyak diminati oleh masyarakat. Produk usaha jasa ini menawarkan 2 luaran produk yang dapat dipilih pelanggan yaitu undangan dan mahar. Desain yang unik dan menyesuaikan selera dari calon pengantin menjadi daya jual tersendiri.
\end{abstract}

Kata Kunci: Undangan; Mahar; Pengantin

\begin{abstract}
Every human being can create entrepreneurship, human creativity is one of the causes of the creation of entrepreneurship, even from the creativity of students themselves can create an entrepreneurship one of them is JANGAN MUPENG (invitation and dowry services for brides). Most of the brides want an event that suits their desires that seems luxurious and elegant but at an affordable price. But most of them have difficulty when finding information about invitations that are trendy and in accordance with the concept of marriage they want. DON'T MUPENG in Samarinda has an excellent opportunity because the invitation and dowry service can adjust to the wishes of the bride and groom. JANGAN MUPENG provides invitations and dowry services for the bride and groom according to their preferences. Judging from the economic condition of the people of Samarinda city who tend to find and buy goods that are cheap but still of high quality, they are optimistic that the service products offered will be in high demand by the public. This service business product offers 2 product outcomes for customers to choose from, namely invitation and dowry. The unique design and customizing the taste of the bride and groom become their selling power.
\end{abstract}

Keywords: Invitation; Dowry; Bridegroom

\section{PENDAHULUAN}

Acara pernikahan sering dijumpai pada gedunggedung atau Kantor Urusan Agama (KUA). Banyak calon pengantin menginginkan acara pernikahan yang terkesan mewah dan elegan namun dengan harga yang terjangkau. Berdasarkan wawancara dari KUA di Kecamatan Samarinda Ulu, terdapat sekitar 60-150 pasangan calon pengantin dalam setiap bulan yang mendaftar di KUA sepanjang tahun 2016. Sebagian besar dari mereka mengalami kesulitan ketika mencari informasi mengenai undangan yang trendi dan sesuai dengan konsep pernikahan yang mereka inginkan. Mayoritas percetakan undangan berada di pulau Jawa, sehingga para calon pengantin yang berada di luar pulau Jawa khususnya di Kalimantan Timur harus memesan dan terkena ongkos kirim yang mahal. Salah satu bisnis yang kini berkembang adalah pembuatan jasa undangan pernikahan (Erlistia, 2019). Jasa ini merupakan salah satu usaha yang mempunyai 
potensi yang sesuai dengan kondisi masyarakat yang masih mengandalkan dari daerah lain (Glendoh, 2013). Selain undangan, mahar merupakan hal penting lainnya yang biasanya ada pada prosesi pernikahan. Mahar merupakan salah satu hak mutlak istri dari terjadinya perkawinan yang diberikan oleh calon suami sebagai ungkapan keinginan seorang pria terhadap seorang perempuan (Damis, 2016). Mahar dapat terbuat dari kertas yang dibentuk dengan unik dan menarik serta mempunyai arti tertentu Damayanti, Sampurna, \& Lasiman, 2009). Mahar dapat terbuat dari kertas, dapat dibentuk seperti burung, hati, dan banyak lagi variasi lainnya. Mahar dapat dipesan sesuai keinginan atau dapat juga bertemakan sesuai konsep pernikahan. Pada mahar dapat dimasukan foto calon pengantin sehingga tampilan semakin unik dan menarik.

JANGAN MUPENG memiliki peluang bagus di Samarinda karena jasa pembuatan undangan dan mahar yang dapat menyesuaikan dengan keinginan dari calon pengantin masih jarang ditemui. Harga yang dipatok sangat terjangkau dan tidak mengurangi kualitas dari produk yang dihasilkan ( Melinda, \& Lestari, 2012). Jenis usaha yang akan dikembangkan adalah berupa jasa, dimana usaha ini diharapkan dapat membantu calon pengantin untuk menunjang kebutuhan para pengantin yang ingin mengadakan acara pernikahan sesuai dengan keinginan mereka. Kelebihan dari produk yang dihasilkan dari usaha JANGAN MUPENG adalah undangan yang trendi dan up to date serta menggunakan bahan kertas yang berkualitas. Undangan akan didesain unik dan menarik dengan perpaduan warna background, gambar dan font yang sesuai sehingga dapat mempercantik penampilan dari undangan tersebut (Damajanti, 2011). Selanjutnya, pengemasan undangan pun juga akan menjadi daya jual tersendiri dengan berbagai jenis pengemasan yang akan ditawarkan, misalnya menggunakan amplop dan tali rami ditambah tag nama gantung dapat menambah kecantikan penampilan undangan (Ayusti, \& Oemar. 2015).

JANGAN MUPENG berpotensi menjadi peluang bisnis bagi mahasiswa karena dapat dijalankan sambil kuliah serta menumbuhkan jiwa kewirausahaan dan kreativitas berbasis Iptek. Penanaman dan pembekalan jiwa wirausaha diharapakan mampu memberi bekal mahasiswa untuk menjadi wirausahawan yang kompetitif (Siswoyo, 2009). Jiwa kewirausahaan dalam jangka panjang mempunyai dampak pada perilaku kewirausahaan dan kemandirian usaha (Sukirman, 2017). Kewirausahaan memerlukan kemampuan kreatif dalam melihat peluang dan mampu berpikir yang positif dalam mengembangkan usahanya (Saragih, 2017). Kuliah sambil berwirausaha adalah pilihan mahasiswa untuk menjadi lebih mandiri dan kreatif agar tidak hanya mengandalkan ijazah sarjana ketika lulus. Usaha JANGAN MUPENG dapat juga membuka lapangan pekerjaan bagi yang membutuhkan.

Tujuan dari kegiatan PKM-K yang berjudul "JANGAN MUPENG" ini adalah menyediakan jasa pembuatan undangan dan mahar bagi calon pengantin sesuai dengan keinginan mereka. Usaha ini dirasa perlu karena di Kalimantan Timur masih sedikit jasa pembuatan undangan dan mahar yang bisa dipesan sesuai dengan keinginan dan dengan harga yang relatif murah.

\section{METODE PELAKSANAAN}

Dalam pembuatan undangan maupun mahar salah satu hal yang perlu diperhatikan adalah terkait pemilihan warna. Saat proses desain pemilihan basic warna untuk background dan foreground harus sesuai (Dameria, 2007). Selain itu, proses cetak maupun kesesuaian media cetak (missal jenis kertas atau jenis tinta) juga perlu diperhatikan (Raharjo 2006).

\section{Undangan}

Proses pembuatan undangan memerlukan beberapa alat dan bahan, yaitu: mesin cetak, alat pemotong, komputer, alat pelipat, kertas, tinta, plastik, stiker nama, dan pita.
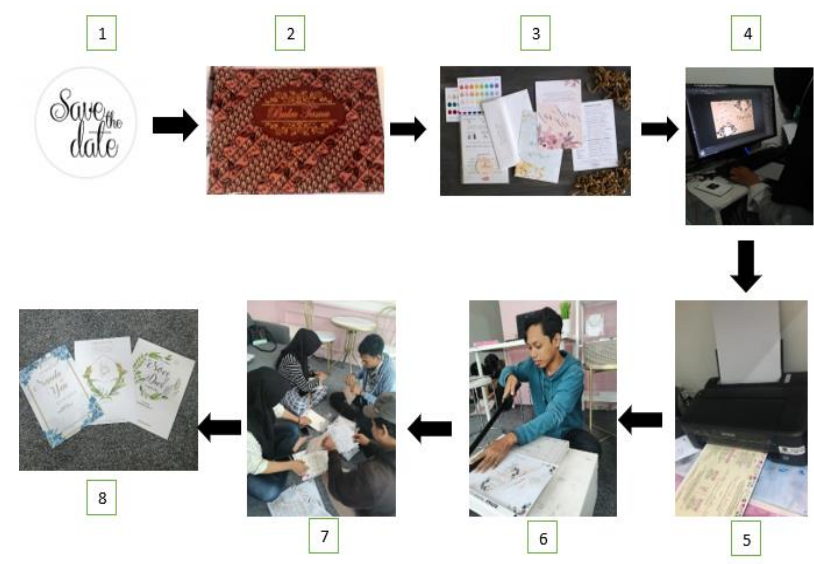

Gambar 1. Pembuatan Undangan

Proses pembuatan undangan adalah sebgaia berikut (Gambar 1):

1. Mengelola bagian undangan: "Save-the-date" biasanya menyertakan pengumuman pertunangan dan pernikahan, nama pasangan, serta waktu pernikahan atau membuat daftar 
tamu untuk mengetahui berapa banyak undangan yang harus dibuat.

2. Merancang undangan idealnya baru dilakukan setelah merencanakan acara pernikahan. Untuk tampilan undangan yang terbaik, penulisan nama, pilihlah warna, motif serta latar yang sesuai dengan dekorasi acara pernikahan.

3. Membuat desain undangan, jika konsumen telah yakin dengan kriteria dan model dari undangan tersebut barulah dibuat desainnya, dari halaman depan hingga isi dari undangan tersebut. Nama pengantin, tempat dan tanggal acara, dan denah lokasi bisa dilakukan dengan memanfaatkan google map.

4. Proses Pencetakan, pastikan design dan kertas telah benar. Untuk mencetak, masukan kertas dengan posisi yang benar begitu juga dengan isinya.

5. Setelah proses melipat undangan. Pada tahapan ini dibutuhkan ketelatenan karena membutuhkan kesabaran dan ketelitian. Pemotongan dan pelipatan kertas dengan menggunakan alat bantu ujung dengan ujung harus rapi.

6. Pada tahap akhir ini pengemasan produk dilakukan dengan menempel label nama dan memasukan kertas ke dalam plastik. Produk pun siap dipasarkan atau siap diberikan kepada konsumen.

\section{Mahar}

Dalam pembuatan mahar memerlukan beberapa alat dan bahan, yaitu : gunting, lem tembak, double tip, frame aksesoris hiasan dan vang kertas,

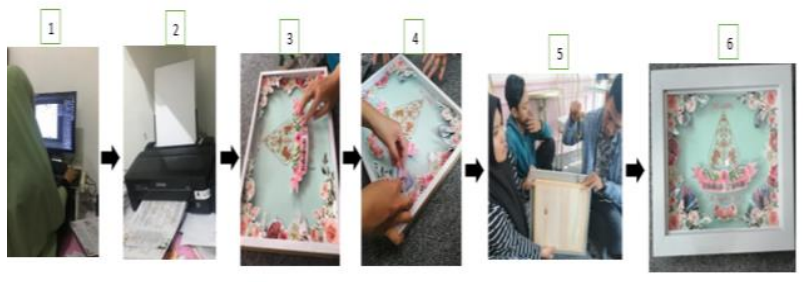

Gambar 2. Pembuatan Mahar

Langkah-langkah pembuatan mahar (Gambar 2) adalah:

1. Pahami design. Membuat design mahar yang telah disepakati oleh konsumen meliputi konsep, tema, pemilihan warna dan motif yang digunakan, serta alat - alat pendukung lainnya.

2. Setelah design disetujui maka tahapan berikutnya adalah mencetak design dari mahar tersebut. Setelah dicetak, gunting bahan sesuai dengan konsep dari mahar maskawin tersebut.

3. Setelah itu cobalah konsep dahulu di atas bingkai. Tata semua bagian-bagian tadi menjadi bentuk yang diinginkan. Agar tampilan mahar lebih menarik, gunakan bantuan accessories di dalamnya. Buatlah lipatan-lipatan uang kertas buat seperti kipas yang diletakkan ujung-ujung frame atau ruang kosong.

4. Setelah semua selesai, barulah tempel bagianbagian ujung frame dengan bunga atau aksesoris lainnya. Ukur lebar bingkai dalam mahar agar ada cukup ruang. Gunakan lem dengan kualitas baik agar mahar menempel kuat. Hatihati menggunakan lem agar tidak berceceran.

5. Kemudian bersihkan kaca frame dengan menggunakan pembersih kaca dan pasang baut pada sudut-sudut frame. Pasang baut dengan benar agar frame tidak mudah lepas.

6. Mahar siap dibingkai. Pemilihan jenis bingkai juga sangat berpengaruh. Mahar biasa jika dikemas bingkai yang bagus maka hasilnya akan istimewa. Pilih bingkai yang senuansa, seirama, jangan kontras.

\section{PEMBAHASAN}

Pada era globalisasi saat ini perkembangan bidang industri jasa di sektor ekonomi, sangat besar dan tumbuh dengan pesat. Adanya usaha jasa yang diperbaharui sesuai dengan tuntutan dan perkembangan teknologi menjadi keharusan agar bisa bersaing saat ini. Salah satu industri jasa yang cukup berkembang yaitu pembuatan undangan dan mahar. Usaha jasa undangan dan mahar di Kota Samarinda sendiri masih sangat sedikit karena harga yang ditawarkan kurang bersahabat. Mayoritas masyarakat memilih harga dibawah standar namun dengan kualitas bagus.

JANGAN MUPENG hadir untuk memenuhi keinginan dari calon pengantin. Perkembangan teknologi dan pengetahuan masyarakat berdampak pada timbulnya berbagai macam desain dan tata bahasa dalam undangan dan mahar pernikahan. Gaya desain pun beraneka ragam, ada yang penuh dengan ukir-ukiran, sulur daun dengan ilustrasi indah, desain minimalis kekinian, dan masih banyak lagi. Beberapa undangan dan mahar pernikahan dipenuhi oleh ornamen-ornamen bunga, tumbuhan yang menawan serta penggunaan foto prewedding. Selain itu penggunaan visualisasi undangan pernikahan yang meliputi gaya desain dan corak undangan pernikahan juga mengalami perkembangan .Menjadi menarik ketika "JANGAN MUPENG" membuat terobosan dengan mengangkat gaya yang khas dan cukup populer dalam desain undangan, antara lain secara eksklusif mengangkat desain unik bertema Vintage. Spesifikasi objek visualisasi pada kartu undangan pernikahan ini menggunakan teknik vektor dan mengeksplorasi bentuk-bentuk yang berwarna. Pemilihan dengan 
komposisi ornamen-ornamen sangat digemari oleh masyarakat. Hal ini dapat dilihat dari jumlah animo pasar undangan serta mahar dengan desain vintage sangatlah banyak. Inilah yang kemudian menjadi pembahasan penting dalam arah perancangan bisnis. JANGAN MUPENG memerlukan terobosan dalam strategi media dan kreatif guna merebut pasar di kota Samarinda.

\section{Undangan}

Pembuatan design dan produk undangan dilakukan pada 28 Mei 2019, pelaksanaan dilakukan di jalan K.S. Tubun oleh seluruh anggota. Desain undangan dibuat menggunakan coreldraw atau photoshop dengan melihat beberapa contoh di google untuk design yang menarik (Gambar 3).

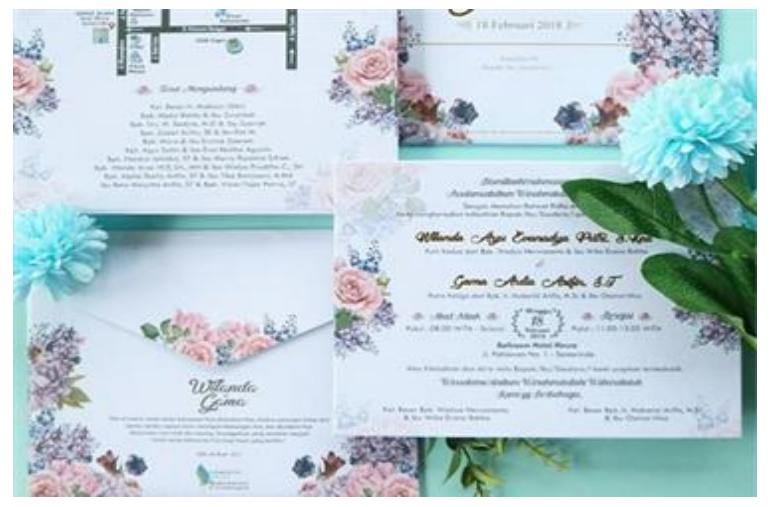

Gambar 3. Produk Undangan

\section{Mahar}

Pembuatan design dan produk mahar dilakukan pada 28 Mei 2019, pelaksanaan dilakukan di jalan K.S. Tubun dilakukan oleh seluruh anggota, dengan arahan keluarga dari salah satu anggota. Seluruh anggota dapat mempelajari bagaimana cara membuat sebuah mahar pengantin secara sederhana menggunakan frame, uang palsu, dan lain-lain (Gambar 4).

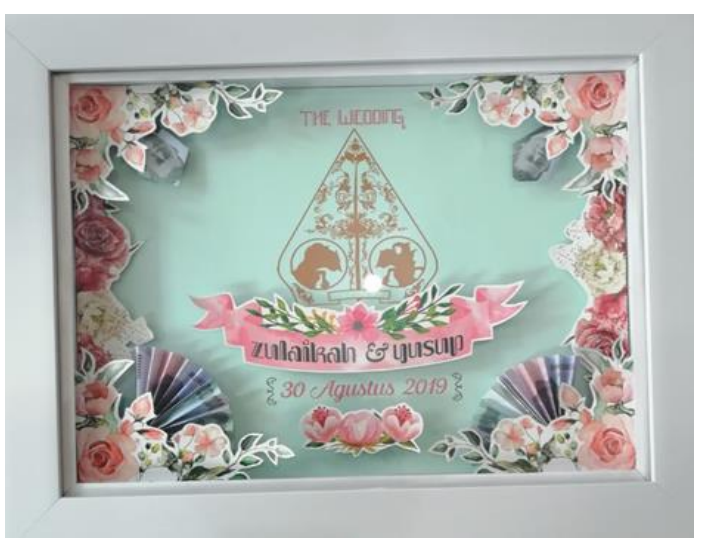

Gambar 4. Produk Mahar

\section{Potensi Pengembangan Usaha}

1. Mampu menciptakan lapangan pekerjaan bagi masyarakat yang terjun di bidang desain.

2. Peluang bisnis yang terbuka karena JANGAN MUPENG (Jasa Undangan dan Mahar untuk Pengantin) bisnis tidak dapat hilang, karena setiap pernikahan membutuhkan undangan.

3. Menambah inovasi dan kreativitas di kalangan desainer untuk terus melakukan update model undangan yang tak kalah bagusnya dengan vendor wedding lainnya.

4. JANGAN MUPENG telah berhasil mendapatkan masing-masing dua pesanan baik untuk mahar dan undangan dan hasilnya sesuai dengan yang diinginkan oleh customer.

\section{KESIMPULAN}

Dari kegiatan yang telah dilaksanakan dapat disimpulkan bahwa kewirausahaan dapat diciptakan oleh setiap manusia. Kreativitas manusia menjadi salah satu penyebab terciptanya suatu kewirausahan, bahkan dari kreativitas mahasiswa sendiri dapat menciptakan suatu usaha, salah satunya adalah JANGAN MUPENG (Jasa undangan dan mahar untuk pengantin). Produk usaha jasa ini menawarkan 2 luaran produk yang dapat pelanggan pilih yaitu undangan dan mahar. Jenis usaha jasa undangan dan mahar ini tidak akan punah oleh waktu, jenis usaha yang menjanjikan karena setiap pernikahan membutuhkan undangan dan mahar. Kegiatan ini membutuhkan promosi yang dapat dilakukan dengan beberapa cara misalnya mengikuti pameran Wedding atau memanfaatkan media sosial untuk meningkatkan pendapatan dan agar lebih dikenal di masyarakat.

\section{UCAPAN TERIMA KASIH}

Kepada Direktorat Jenderal Penguatan Riset dan Pengembangan Kementerian Riset, Teknologi, dan Pendidikan Tinggi Republik Indonesia yang telah mendanai Program Kreativitas Mahasiswa tahun 2019.

\section{DAFTAR PUSTAKA}

Ayusti, R.A \& Oemar, E, A.B, 2015. Desain Periklanan Wedding Organizer Artio Perancangan Desain Periklanan sebagai Media Promosi Wedding Organizer Artio. Jurnal Seni Rupa, 3(03), 95-103

Damajanti, M. N. 2011. Keindahan Versus Narsisme Dalam Undangan Pernikahan. Nirmana 12(1), 20-25.

Damayanti, M. N., Sampurna, B., \& Lasiman, L. (2009). Gaya Desain pada Visualisasi Undangan Pernikahan di Surabaya. Nirmana, 11 (1), 19-32.

Dameria, A. 2007. Color Basic Panduan Dasar Warna untuk Desainer dan Industri Grafika. Jakarta: Link and Match Graphic.

Damis, H.. 2016. Konsep Mahar Dalam Perspektif Fikih Dan Perundang-Undangan. Jurnal Yudisial 9(1), 19-35. 
Maulidiah, et., al, Jurnal Pengabdian Masyarakat Wikrama Parahita 2020, Volume 4 Nomor 1: 58-62 DOI: http://dx.doi.org/10.30656/jpmwp.v4i1.1871

Erlistia, E. 2019. Perancangan Desain Web Dan Instagram Undangan Pernikahan 'Anytime Wedding Invitation. Ars: Jurnal Seni Rupa dan Desain 21 (1), 46-65.

Glendoh, S. H. 2013. Pembinaan dan pengembangan usaha kecil. Jurnal Manajemen dan Kewirausahaan 3 (1): $1-13$.

Melinda, \& Lestari, C. 2012. Rancang Bangun Sistem Undangan Online Berbasis Web Pada Webinvito Design. 9-16.

Saragih, R. 2017. Membangun Usaha Kreatif, Inovatif Dan Bermanfaat Melalui Penerapan Kewirausahaan Sosial. Jurnal Kewirausahaan 3(2):26-34.

Siswoyo, B.B. 2009. Pengembangan jiwa kewirausahaan di kalangan dosen dan mahasiswa. Jurnal Ekonomi Bisnis. 14 (2): 114-23.

Sukirman. 2017. Jiwa Kewirausahaan Dan Nilai Kewirausahaan Meningkatkan Kemandirian Usaha Melalui Perilaku Kewirausahaan. Jurnal Ekonomi dan Bisnis. 20(1): 113-132. 